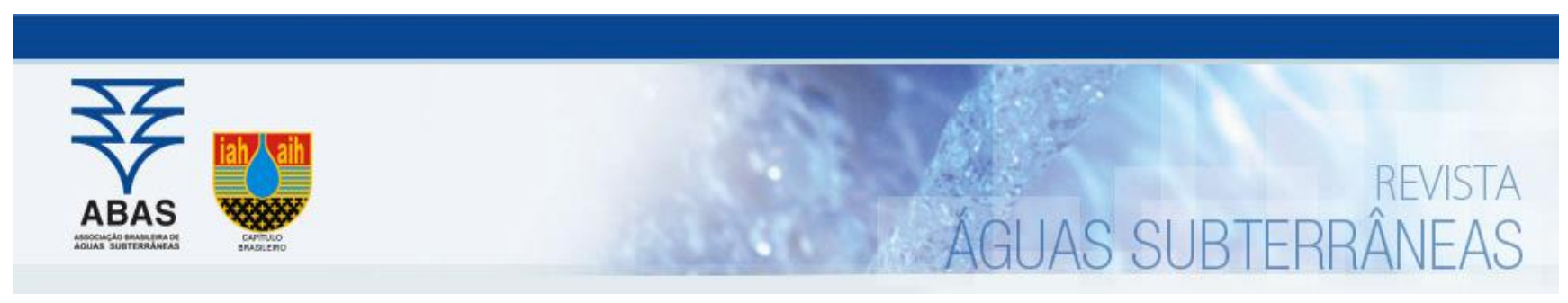

Artigos

\title{
Análise da compartimentação estrutural do sistema aquífero embasamento cristalino no município de Bagé (RS) com base no uso de lineamentos (SRTM e magnéticos) e de dados hidrogeológicos
}

\author{
Analysis of the structural compartiment of the crystalline basement aquifer \\ system in the municipality of Bagé (RS) based on the use of lineaments \\ (SRTM and magnetic) and hydrogeological data
}

\author{
Rafael Lima Dessart1; Pedro Antonio Roehe Reginato1; Cristiane Heredia Gomes²; Jacson Gosman Gomes de Lima ${ }^{\circledR}$ \\ 1 Instituto de Pesquisas Hidráulicas (IPH) / Universidade Federal do Rio Grande do Sul (UFRGS), Porto Alegre, RS \\ 2 Universidade Federal do Pampa (UNIPAMPA), Caçapava do Sul, RS \\ 3 Instituto Federal de Santa Catarina (IFSC), São Miguel do Oeste, SC
}

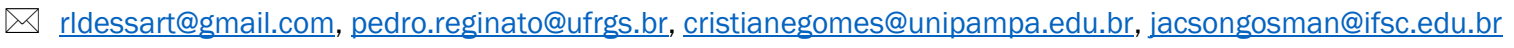

Palavras-chave:

Sistema Aquífero Cristalino. Aeromagnetometría. Compartimentação Estrutural e Hidrogeologia.

\section{Resumo}

Esse artigo apresenta o estudo de avaliação da compartimentação e do comportamento hidrogeológico do Sistema Aquífero Embasamento Cristalino, no município de Bagé (RS). Para realização desse estudo, foram utilizados dados hidrogeológicos de 174 poços tubulares e dados de lineamentos obtidos de imagens SRTM e de levantamento aerogeofísico. Para realizar a avaliação estrutural da área, foram traçados lineamentos morfoestruturais nas imagens SRTM, em diferentes escalas (1:1.000.000; 1:500.000 e 1:250.000), bem como foram identificadas estruturas por meio da análise e interpretação dos dados aeromagnéticos. Esses dados foram utilizados visando identificar a existência de compartimentos estruturais. Os dados dos poços tubulares foram analisados e utilizados na caracterização hidrogeológica da área de estudo e dos compartimentos estruturais. Os resultados indicaram a ocorrência de cinco estruturas principais, que possuem extensões entre 8,62 e $30 \mathrm{~km}$. Com base nessas estruturas, foram definidas cinco zonas (Z1 a Z5) que possuem características distintas. A Zona 1 apresenta os principais trends para N80-90E e N60-70E, capacidade específica de $0,005 \mathrm{~m}^{3} / \mathrm{h} / \mathrm{m}$ e vazão de $0,46 \mathrm{~m}^{3} / \mathrm{h}$. Na Zona 2 os principais trends são para N20-30E, N50-60E e N30-40E, a capacidade específica máxima é de $6,93 \mathrm{~m} 3 / \mathrm{h} / \mathrm{m}$, com vazão máxima de $16,5 \mathrm{~m}^{3} / \mathrm{h}$. Na Zona 3 os trends são N50-60E, N40-50E e N30-40E, com capacidade específica máxima de $3 \mathrm{~m} 3 / \mathrm{h} / \mathrm{m}$ e vazão máxima de $20,37 \mathrm{~m}^{3} / \mathrm{h}$. $\mathrm{Na}$ Zona 4 os principais trends são para N70-80E e N20-30E, com capacidade específica máxima de $2,13 \mathrm{~m} 3 / \mathrm{h} / \mathrm{m}$ e vazão máxima de $12 \mathrm{~m}^{3} / \mathrm{h}$. Por fim, na Zona 5 os trends principais são para N70-80E, N20-30E e N00-10W, com capacidade específica máxima de $1,5 \mathrm{~m}^{3} / \mathrm{h} / \mathrm{m}$ e vazão máxima de $30 \mathrm{~m}^{3} / \mathrm{h}$. Esses resultados demonstram que a região do município de Bagé se apresenta compartimentada, com zonas apresentando diferentes produtividades e trends estruturais, sendo que a Zona 2 apresenta estruturas que estão associadas a maior produtividade de poços. Assim, a análise de lineamentos magnéticos e morfoestruturais, demonstra ser um estudo que tem importância na avaliação da compartimentação estrutural e hidrogeológica de áreas com ocorrência de aquíferos fraturados.

Abstract

Keywords:

Crystalline Aquifer System. Aeromagnetometry. Structural Compartmentation and Hydrogeology.

Revisado por pares. Recebido em: 24/05/2019. Aprovado em: 19/12/2019.
This paper presents the study for defining hydrogeological compartments of the Crystalline Basement Aquifer System, in the municipality of Bagé (RS). For this study, hydrogeological data from 174 tubular wells and lineaments data obtained from SRTM images and aerogeophysical survey were used. To perform the structural assessment of the area morphostructural lineaments on the SRTM images in different scales (1: 1,000,000; 1: 500,000 and 1: 250,000) were traced, as well as structures were identified by analyzing and interpreting aeromagnetic data. These data were used to identifying the existence of structural compartments. Data from the tubular wells were analyzed and used for the hydrogeological characterization and the structural compartments in the studied area. The results indicated the occurrence of five main structures, presenting lengths between 8.62 and $30 \mathrm{~km}$. Based on these structures five zones (Z1 to Z5) with distinct characteristics were defined. Zone 1 show the main trends as N80-90E and N60-70E and specific capacity of $0.005 \mathrm{~m}^{3} / \mathrm{h} / \mathrm{m}$ and flow rate of $0.46 \mathrm{~m}^{3} / \mathrm{h}$. In Zone 2 the main trends range between N20-30E, N50-60E and N30$40 \mathrm{E}$, with a maximum specific capacity of $6.93 \mathrm{~m}^{3} / \mathrm{h} / \mathrm{m}$ and a maximum flow rate of $16.5 \mathrm{~m}^{3} / \mathrm{h}$. In Zone 3 , the trends are N50-60E, N40-50E and N30-40E, with a maximum specific capacity of $3 \mathrm{~m} 3 / \mathrm{h} / \mathrm{m}$ and a maximum flow rate of 20.37 $\mathrm{m}^{3} / \mathrm{h}$. In Zone 4, the main trends range from N70-80E to N2O-30E, with maximum specific capacity of $2.13 \mathrm{~m} 3 / \mathrm{h} / \mathrm{m}$ and a maximum flow rate of $12 \mathrm{~m}^{3} / \mathrm{h}$. Finally, the main trends in Zone 5 are N70 -80E, N20-30E and NO0-10W, with a maximum specific capacity of $1.5 \mathrm{~m}^{3} / \mathrm{h} / \mathrm{m}$ and a maximum flow rate of $30 \mathrm{~m}^{3} / \mathrm{h}$. Therefor these results show that the region of the municipality of Bagé is divided into zones presenting different productivity and structural trends, empha- 
sizing that Zone 2 has structures with higher productivity. Thus, the analysis of magnetic and morphostructural lineaments proves to be an important technique for evaluation of structural and hydrogeological compartmentalization of areas with occurrence of fractured aquifers.

DOI: http:/dx.doi.org/10.14295/ras.v34i1.29557

\section{INTRODUÇÃO}

A porção meridional do Estado do Rio Grande do Sul passa por recorrentes períodos de estiagem, com isso prejudicando o abastecimento público e o desenvolvimento de atividades agrícolas, industriais e comerciais. Para solucionar esse problema, nas áreas municipais que em geral tem o abastecimento urbano realizado por empresa pública, a busca por água ocorre por meio da perfuração de poços tubulares. Nas áreas rurais, a solução encontrada é feita de forma individual ou coletiva, por meio da perfuração de poços tubulares ou através da captação da água da chuva e de nascentes.

A frequência de anos considerados secos é maior no sul do que no norte do Estado, sendo que nas áreas de Campanha e Baixo Vale do Uruguai, a frequência média de anos secos atinge $20 \%$. Nessas regiões do Estado ocorrem as mais intensas e extensas estiagens (BERLATO, 1992, LEIVAS et al., 2006).

Conforme Varone et al. (2011), a análise dos totais anuais de chuva através do método dos quantis, em Bagé/RS, mostrou que eventos de secas são recorrentes na região. Entre os anos de 1912 e 1960 ocorreu a maior parte dos casos, e nas últimas três décadas somente seis anos apresentaram valores referentes aos intervalos de secos ou muitos secos. Já a taxa de retorno de eventos de seca foi de 2,8 anos.

Conforme o Departamento de Água, Arroios e Esgoto de Bagé (DAEB, 2018), o sistema de abastecimento público é realizado através da captação de água em três barragens, denominadas de: Emergencial, Piray e Sanga Rasa. Além disso, como reforço, em períodos de estiagem, são utilizados poços tubulares para captação de água subterrânea, sendo que essa água é direcionada para as barragens e estações de tratamento.

No município de Bagé, há ocorrência do Sistema Aquífero Embasamento Cristalino, que é caracterizado por aquíferos fraturados que estão associados às litologias do Complexo Granítico-Gnáissico Bagé (TAMBARA, 2013). Conforme Machado e Freitas (2005), os aquíferos desse sistema estão associados às estruturas tectônicas que cortam as rochas graníticas e metamórficas (gnaisses e filitos), sendo que a circulação e o armazenamento da água vai estar condicionado à ocorrência dessas estruturas. Em geral, esses aquíferos apresentam capacidade específica inferior a $0,5 \mathrm{~m}^{3} / \mathrm{h} / \mathrm{m}$, sendo que nas áreas de ocorrência de rochas graníticas, as águas podem estar enriquecidas em flúor.

Os poços perfurados no Complexo Grano-Gnáissico em Bagé, apresentam baixa produção, sendo que muitos desses poços são locados e perfurados sem estudos prévios, bem como em regiões onde há pouco conhecimento sobre os condicionantes geológicos e estruturais dos aquíferos existentes na área (DAEB, 2018).
O estudo sobre os condicionantes geológicos e estruturais deaquíferos fraturados pode ser realizado com base na avaliação de dados geológicos, estruturais e hidrogeológicos. Fernandes et al. (2008) desenvolveram estudos para avaliar o potencial dos aquíferos fraturados no estado de São Paulo, sendo que essa avaliação foi realizada com base nos condicionantes geológicos, sendo a identificação e avaliação de estruturas um dos principais fatores.

Nesse contexto, a análise e interpretação de dados aeromagnéticos em estudos hidrogeológicos, tem se mostrado eficiente, principalmente, na identificação de estruturas geológicas. Diversos autores realizaram estudos semelhantes utilizando estes dados, como por exemplo, Hewaidy et al. (2015), Ranganai et al. (2017) e Bongiolo et al. (2014). Neste último, os autores utilizaram mapas aeromagnéticos no estudo da conectividade e compartimentação magnético-estrutural no centro do estado do Paraná. Os autores, com base na interpretação de estruturas de subsuperfície (lineamentos magnéticos) e de superfície (lineamentos SRTM), realizaram a identificação de novas estruturas com direções NW e EW.

Este estudo teve por objetivo realizar uma análise e avaliação da ocorrência de compartimentos estruturais, que podem influenciar nos processos de formação dos aquíferos fraturados e da capacidade de produção dos poços tubulares. Essa avaliação foi realizada com a integração dos dados estruturais (lineamentos morfoestruturais), geofísicos (lineamentos magnéticos) e hidrogeológicos (capacidade específica e vazão). Com base nos resultados obtidos foi possível avaliar a existência de compartimentos estruturais que possuem relação com a produção de poços.

\section{LOCALIZAÇÃO E CARACTERIZAÇÃO DA ÁREA DE ESTUDO}

O município de Bagé está localizado na região sudoeste do Rio Grande do Sul, sendo que sua economia, conforme informações da Prefeitura municipal de Bagé, está centrada principalmente na agricultura, na pecuária, e no desenvolvimento de atividades industriais (predominantemente do benefício de laticínios) e comerciais (Figura 1).

Com base na Geomorfologia, a área está inserida em duas principais unidades (IBGE, 1995) a Depressão Central Gaúcha e o Planalto de Caçapava do Sul. A Depressão Central Gaúcha consiste em vasta depressão periférica suportada por rochas da sequência permotriássica da Bacia do Paraná. O Planalto de Caçapava do Sul se caracteriza por um vasto arqueamento crustal, gerando um planalto desnudado em formato dômico ou uma paleoabóboda (AB'SABER, 1998), regionalmente englobado na denominada Campanha Gaúcha.

Conforme Camozzato et al. (2014) a região de estudo é composta pelo Complexo Granitico-Gnaissico Bagé (ortognaisses e granitóides monzo a granodioríticos foliados, com megaxenofilitos de rochas supracrustais) e a Formação Santo Afonso 
(granodioritos e monzogranitos dominantes, com sienogranitos e tonalitos subordinado). Também há ocorrência de rochas sedimentares que estão associadas as formações geológicas
Rio Bonito, Palermo, Irati e Santa Tecla, bem como Depósitos aluviais (FREITAS, 2010).

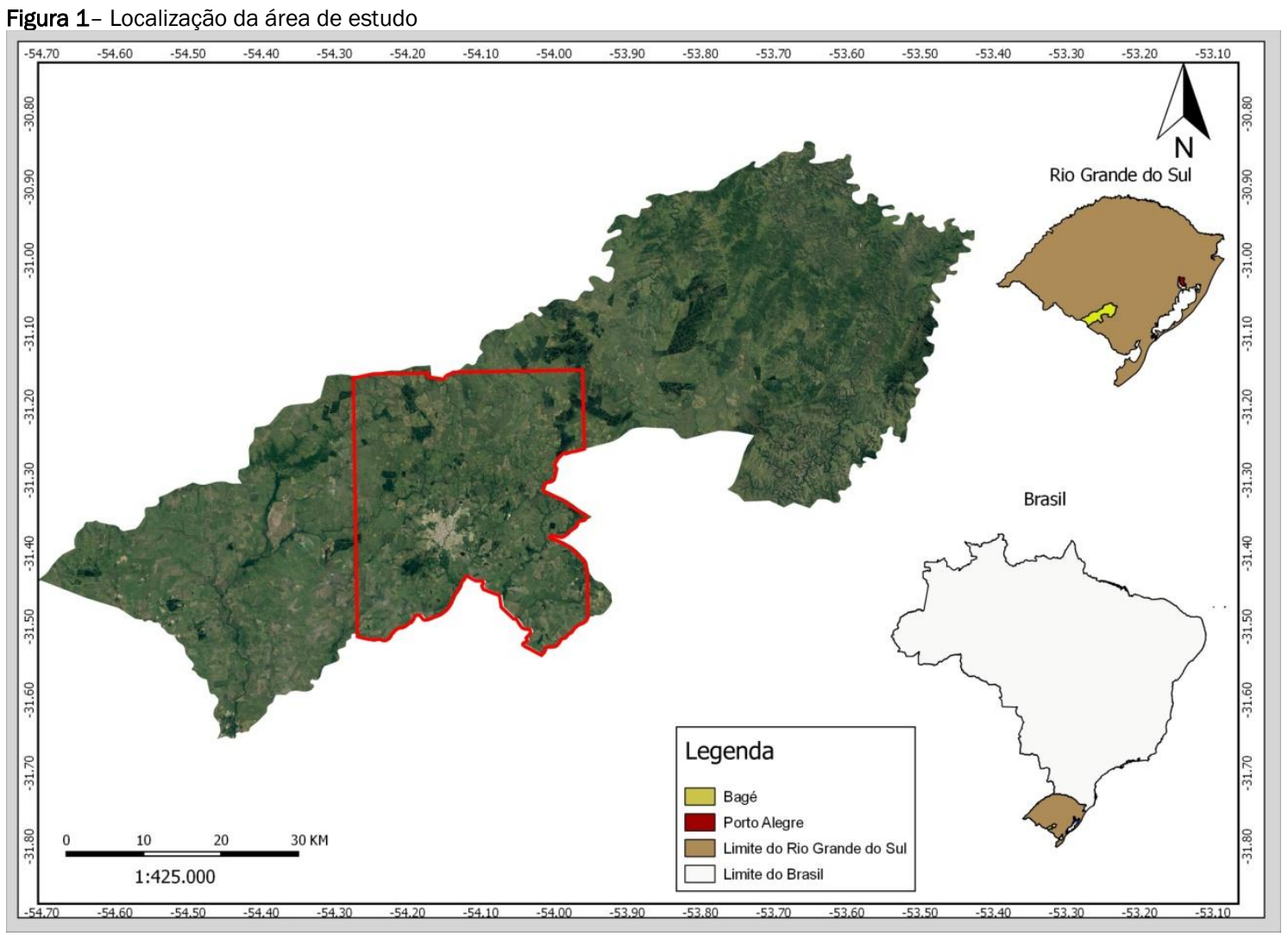

De acordo com Trainini et al. (2005), a hidrogeologia da região de estudo é caracterizada pela ocorrência do Aquiclude EoProterozóico (poços secos ou com vazões insignificantes), do Sistema Aquífero Embasamento Cristalino II (aquíferos limitados de baixa possibilidade para ocorrência de água subterrânea), dos Aquitardos Permianos e do Sistema Aquífero Palermo/Rio Bonito. Esse último sistema, é considerado como aquíferos com baixa a média possibilidade para ocorrência de água subterrânea, sendo que as capacidades específicas são inferiores a $0,5 \mathrm{~m}^{3} / \mathrm{h} / \mathrm{m}$ e as salinidades variam entre $800 \mathrm{e}$ $1500 \mathrm{mg} / \mathrm{I}$ (em grandes profundidades as águas podem apresentar sólidos totais dissolvidos superiores a $10.000 \mathrm{mg} / \mathrm{l}$ ). Em função disso, o Sistema Aquífero Embasamento Cristalino passa a ser o principal sistema, que é utilizado na região de ocorrência do município de Bagé.

\section{MATERIAL E MÉTODOS}

As atividades e métodos, desenvolvidas e empregados nesse estudo, estiveram relacionadas com levantamentos, análises e interpretações de dados geológicos (lineamentos morfoestruturais), geofísicos (lineamentos magnéticos) e hidrogeológicos, sendo que as mesmas são apresentadas no fluxograma da Figura 2.

Para a extração dos lineamentos morfoestruturais, foram utilizadas as imagens SRTM (Shuttle Radar Topography Mission
- NASA), com resolução de 30m (USGS). A partir destas foi gerado o modelo de elevação do terreno nas escalas 1:1.000.000, 1:500.000 e 1:250.000, obtidas a partir do software QGIS. Para a interpretação e extração das estruturas foi utilizada a técnica de falsa iluminação, nas direções NW e NE, tendo gerado duas imagens de relevo sombreado com azimute de $45^{\circ}$ e $315^{\circ}$ (SANTOS et al., 2006).

Os dados utilizados para a análise e processamentos aerogeofísicos foram obtidos no Projeto Estudo do Rio Grande do Sul (CPRM, 2010), composto por 633 linhas de voo (N-S) e 34 linhas de controle na direção leste oeste, perfazendo um total de $159.789,21 \mathrm{~km}$ de perfis e abrangendo uma área de $75.000 \mathrm{~km}^{2}$ na região sul do estado.

A extração dos lineamentos a partir dos dados Aerogeofísicos, foi realizada com base nos dos dados disponíveis no formato GDB`s (Geosotf Database) da CPRM. Estes dados reúnem as informações de posicionamentos corrigidos e os demais canais já ajustados dos dados, registrados em equipamento instalado na aeronave.

Os dados aeromagnéticos foram extraidos do campo magnético principal (IGRF - International Geomagnetic Reference Fild), interpolados em uma grade regular de $100 \mathrm{~m}$ de tamanho de célula (1/4 do espaçamento original das linhas de voo) e utilizando o interpolador pelo método BiDirecional (GEOSOFT, 2013). 
Figura 2 - Fluxograma da metodologia utilizada no desenvolvimento do estudo

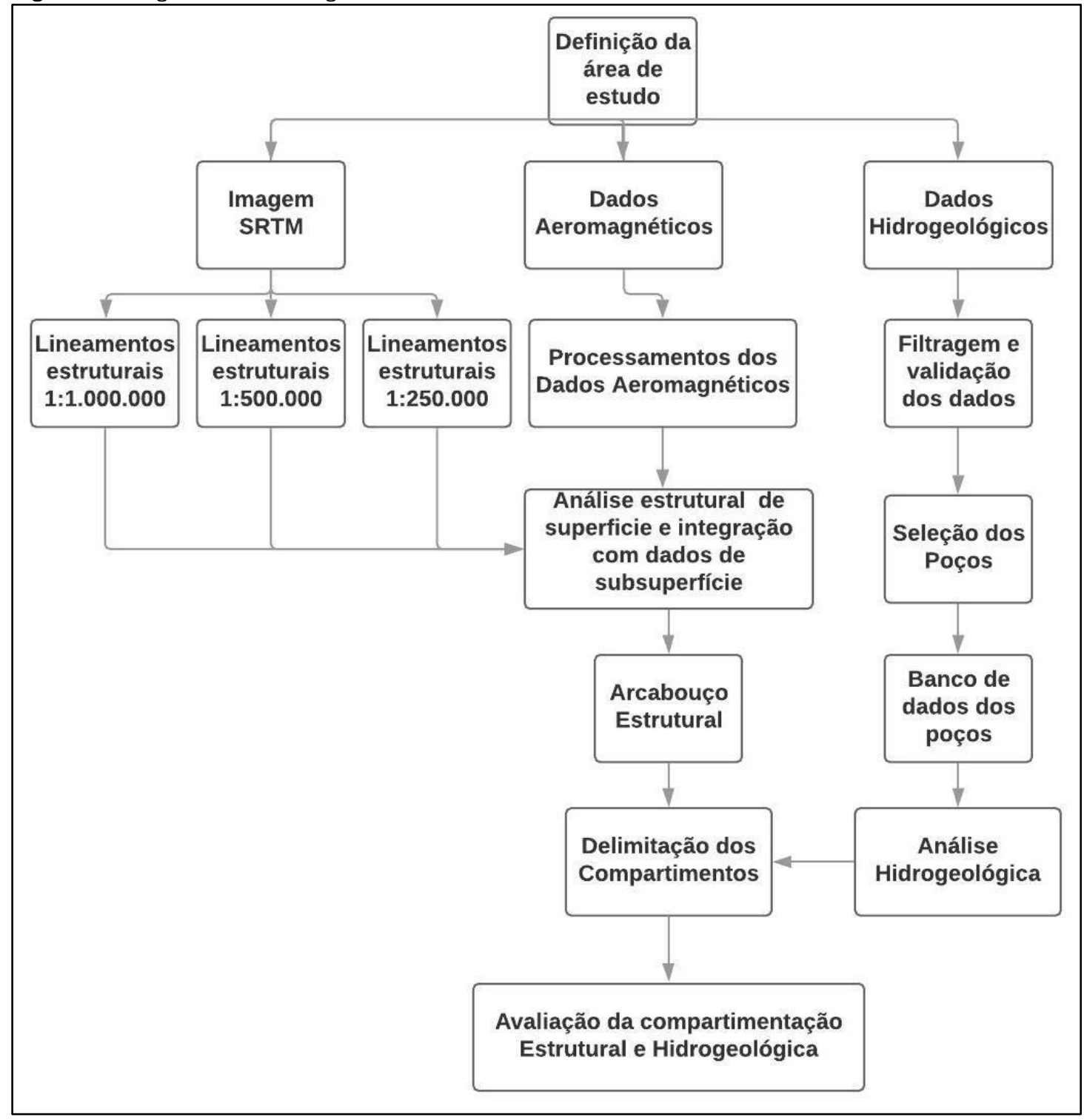

Para a geração dos Grids, da análise estrutural, os dados passam pelo processo de "continuação para cima", simulando aquisição dos dados a uma altitude mais elevada dos dados originalmente adquiridos, neste caso 500m. Este procedimento é realizado para remover ou minimizar os sinais de fontes rasas e ruídos, tornando assim os produtos mais passiveis de uma interpretação que corresponda a realidade da área estudada.

Para a interpretação das anomalias magnéticas associáveis a lineamentos foram utilizados os diversos métodos de realce. Os métodos de realce gerados foram Amplitude do Sinal Analítico (ASA) e Derivada Vertical (GZ), a partir do mapa de anomalias magnéticas de Redução ao Polo Continuado para Cima 500 metros. Os lineamentos foram interpretados seguindo a metodologia tradicional (FERREIRA et al., 2010; PEREIRA E FERREIRA, 2018; CASTRO, 2014), onde são marcados os lineamentos correspondentes aos maiores valores magnéticos.

A análise das principais direções dos lineamentos obtidos das imagens de relevo sombreado e dos dados aeromagnéticos foram realizadas por meio da geração e análise de diagramas de roseta, elaborados com a ferramenta Line Direction Histogram, do software QGIS 2.18.4.

A correlação entre os lineamentos morfoestruturais e os lineamentos magnéticos foi realizada por meio da geração de mapas integrados das estruturas, utilizando o software QGIS 2.18.4. Essa correlação permitiu identificar a ocorrência de estruturas semelhantes, identificadas em ambos os produtos (SRTM e dados aeromagnéticos), bem como estruturas novas (dados aeromagnéticos). Com base na ocorrência de estruturas (lineamentos SRTM e magnéticos) de maior porte e que cortavam a área de estudo, foi possível identificar a ocorrência de blocos estruturais, evidenciando a existência de uma compartimentação estrutural.

A avaliação hidrogeológica foi feita com base na obtenção, análise e interpretação de dados de poços tubulares existentes na região. A identificação e cadastro de poços foi feita junto ao DRH/SEMA (Departamento de Recursos Hídricos da Secretaria Estadual do Meio Ambiente), CORSAN (Companhia Rio-grandense de Saneamento), SIAGAS (Sistema de Informações de Águas Subterrâneas) e empresas de perfuração (Hidrogeo e Georepp). Nesse levantamento foram identificados 
257 poços tubulares, sendo que 174 destes poços possuíam dados do perfil geológico e construtivo e teste de bombeamento.

A avaliação da compartimentação estrutural e hidrogeológica, foi realizada por meio da geração de mapas de capacidade específica e vazão que foram correlacionados com os dados de lineamentos, existentes em cada um dos compartimentos estruturais que foram definidos para a área. Com isso, foi possível avaliar a ocorrência de zonas, caracterizadas pela ocorrência de diferentes estruturas e produtividades dos poços tubulares.

\section{RESULTADOS}

\subsection{Análise e Interpretação de Lineamentos Morfoestrutu- rais}

O Modelo de Elevação do Terreno (MET) foi utilizado com a finalidade de compreender as variações do relevo e identificar a ocorrência de lineamentos morfoestruturais. Conforme o modelo (Figura 3), as variações ocorrem no intervalo de 122 a $391 \mathrm{~m}$, sendo as maiores elevações na porção norte e com declive suave.

\subsection{Lineamentos em escala 1:1.000.000}

$\mathrm{Na}$ interpretação dos lineamentos do mapa em escala 1:1.000.000 (Figura 3), foram identificados 57 lineamentos, com maior destaque para aqueles com direção NE (N20-40E), seguida de ENE (N80-90E), com ocorrências secundárias NNE (NO-10E) e NW (N30-40W e N60-70W). Assim foi possível observar que ocorrem 14 lineamentos na área de estudo com 10 a $30 \mathrm{~km}$, com predomínio de suas direções para Nordeste.

Segundo estas informações, foi possível identificar cinco lineamentos principais com extensões variando de 8,62 a $30 \mathrm{~km}$, sendo estes concordantes ou encaixados em canais de baixa ordem hierárquica, como arroios.

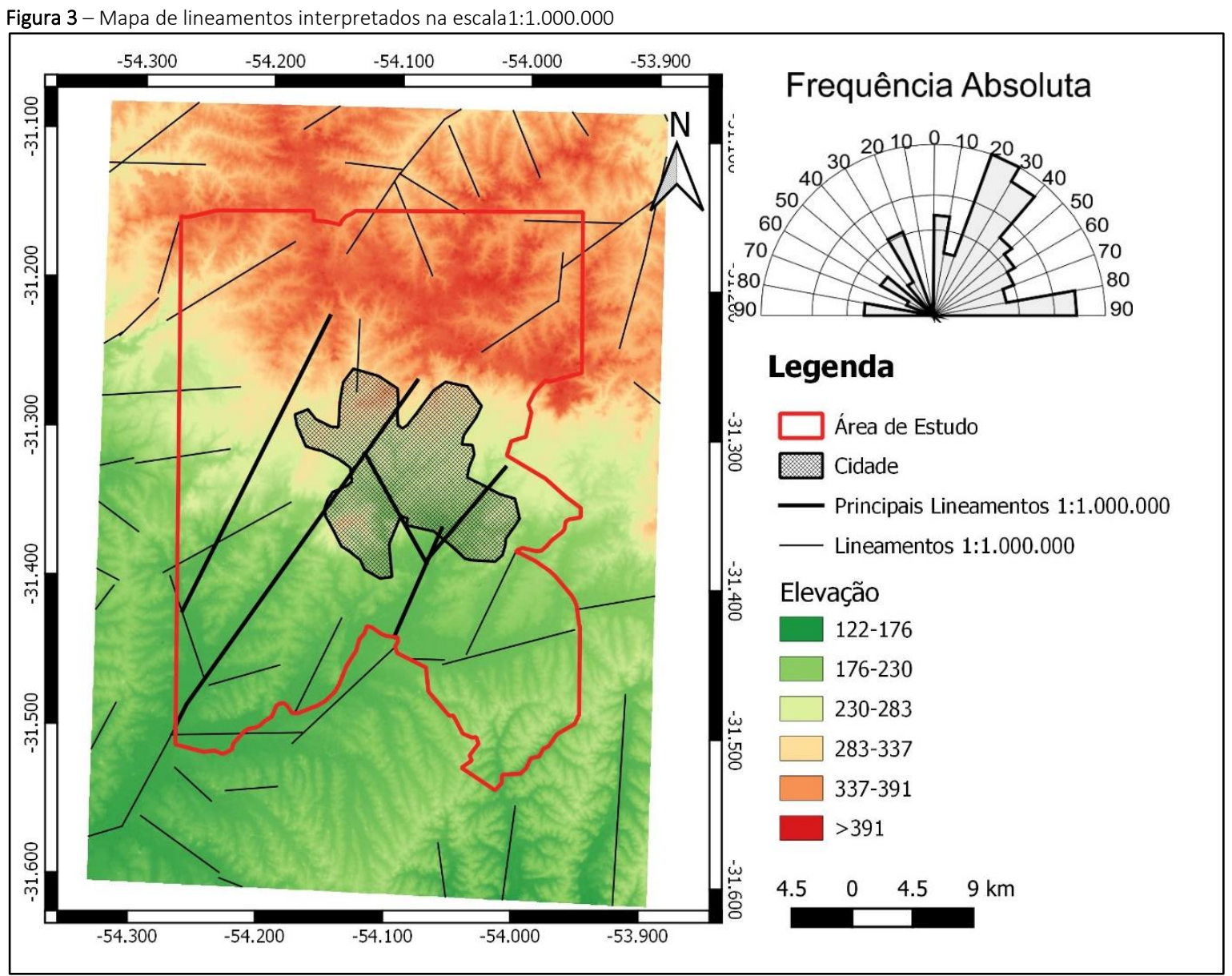

\subsection{Lineamentos em escala 1:500.000}

Na interpretação do mapa em escala 1:500.000, foi possível

identificar 97 lineamentos (Figura 4), com maior destaque para NE (N30-50E), seguida de ENE (N70-80E), com ocorrências secundárias NNW (NO-20W) e NW (N50-70W).

\subsection{Lineamentos em escala 1:250.000}

Na interpretação do mapa em escala 1:250.000 foram marcados cerca de 260 lineamentos (Figura 5). Foi possível observar uma maior dispersão das direções de lineamentos, diferentemente dos mapas anteriores, além do predomínio ENE (N70-90E) e NE (N40-60E), também ocorrem com grande destaque as direções NNW (N10-20W) e NW (N50-70W). 
Figura 4 - Mapa de lineamentos interpretados na escala 1:500.000

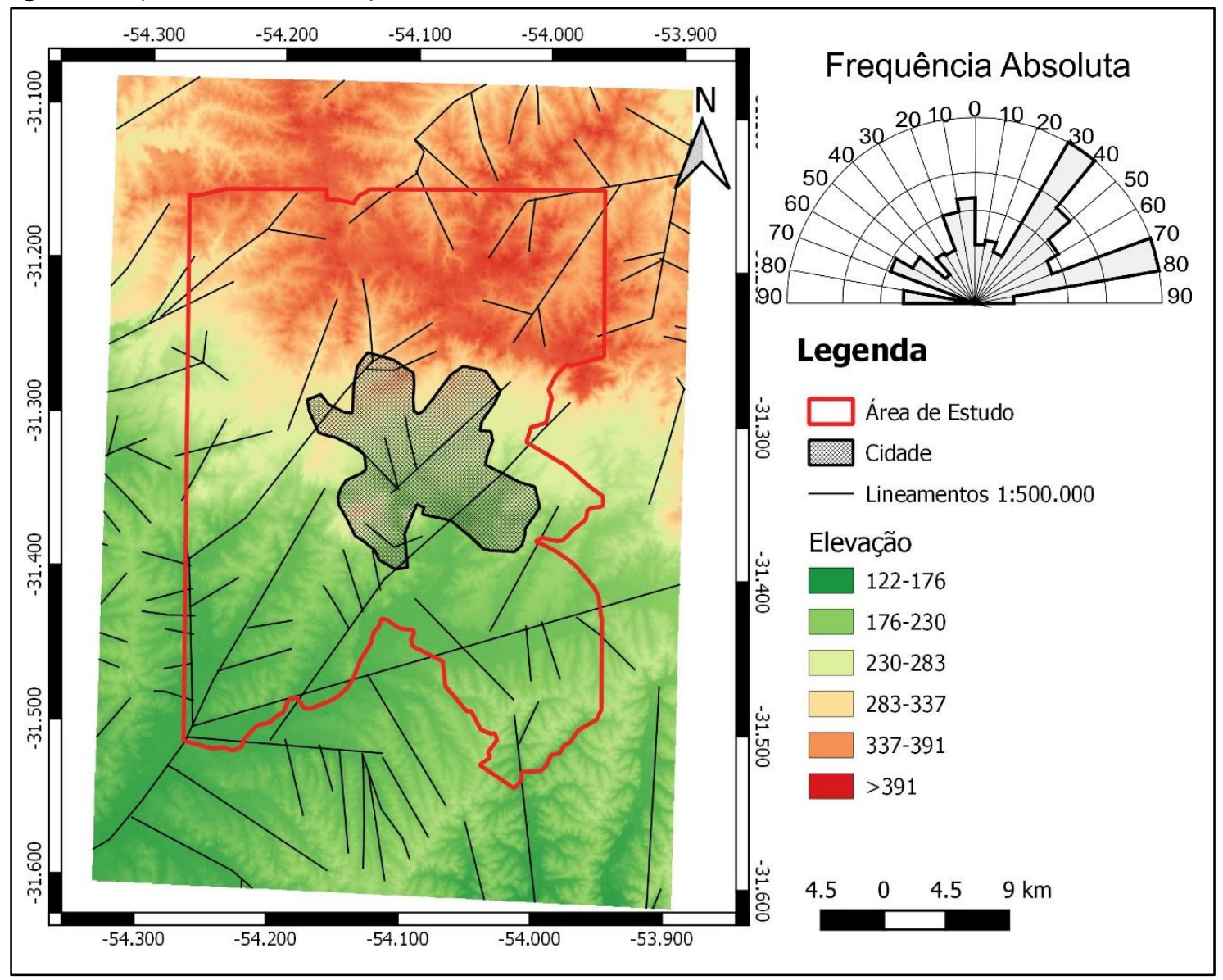

Figura 5 - Mapa de lineamentos interpretados na escala 1:250.000

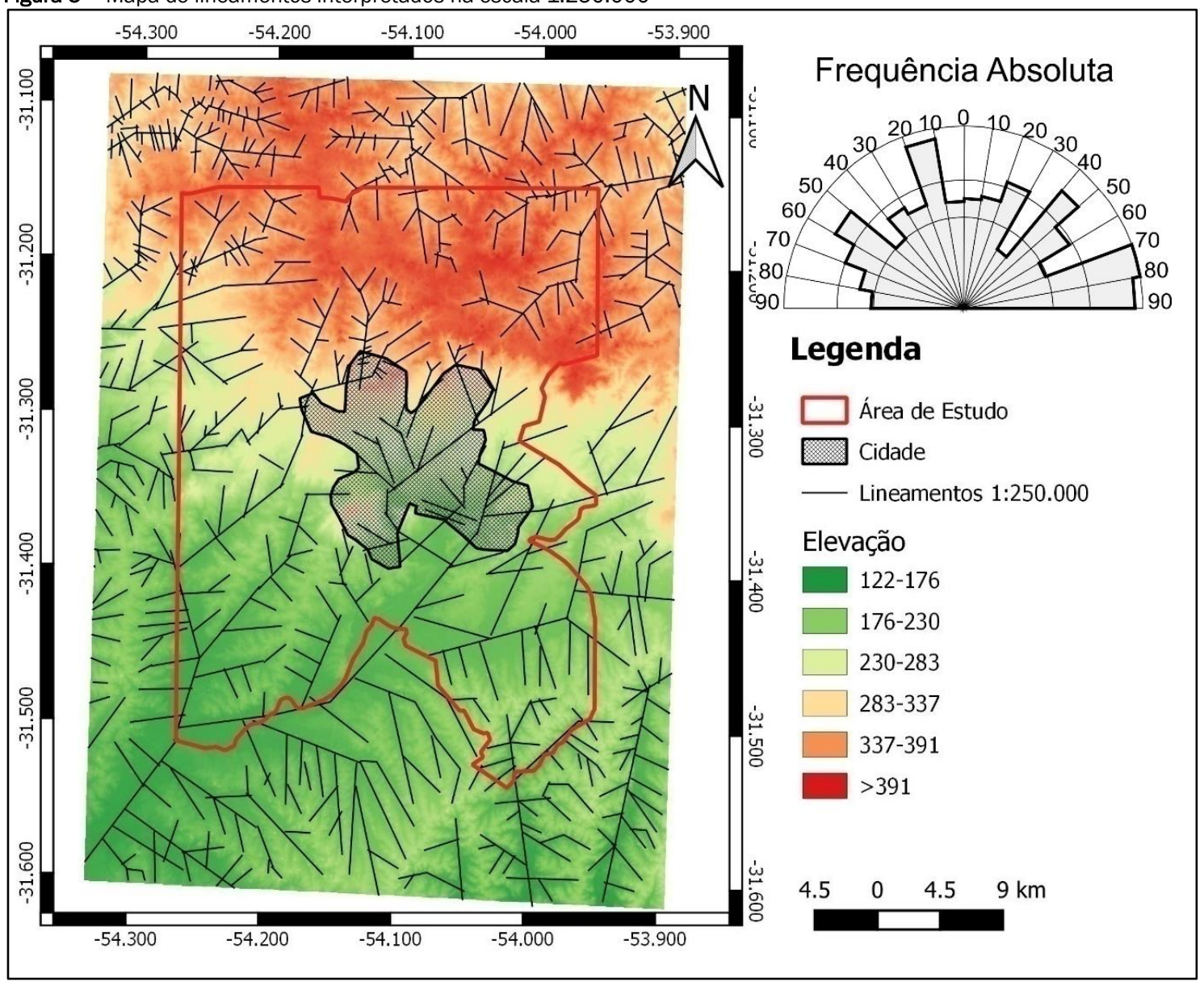




\subsection{Análise e Interpretação de Lineamentos Magnéticos}

Nos mapas de realce dos dados aeromagnéticos, ASA e GZ, foram identificados um total de 492 lineamentos, para a área de estudo. Estes destacaram a ocorrência de estruturas regionais magnéticas-estruturais, que são apresentados na escala 1:430.000.

\subsection{Amplitude do sinal analítico (ASA)}

O mapa da Amplitude do Sinal Analítico (ASA) apresenta as estruturas magnéticas na escala 1:430.000. Neste foram identificados cerca de 246 lineamentos (Figura 6), com direção principal Nordeste e Noroeste, sendo que as principais orientações são N60-70W e N50-80E.

Figura 6- Mapa do arcabouço magnético-estrutural com a interpretação dos lineamentos identificados (linha continua) e inferidos (linha tracejada).

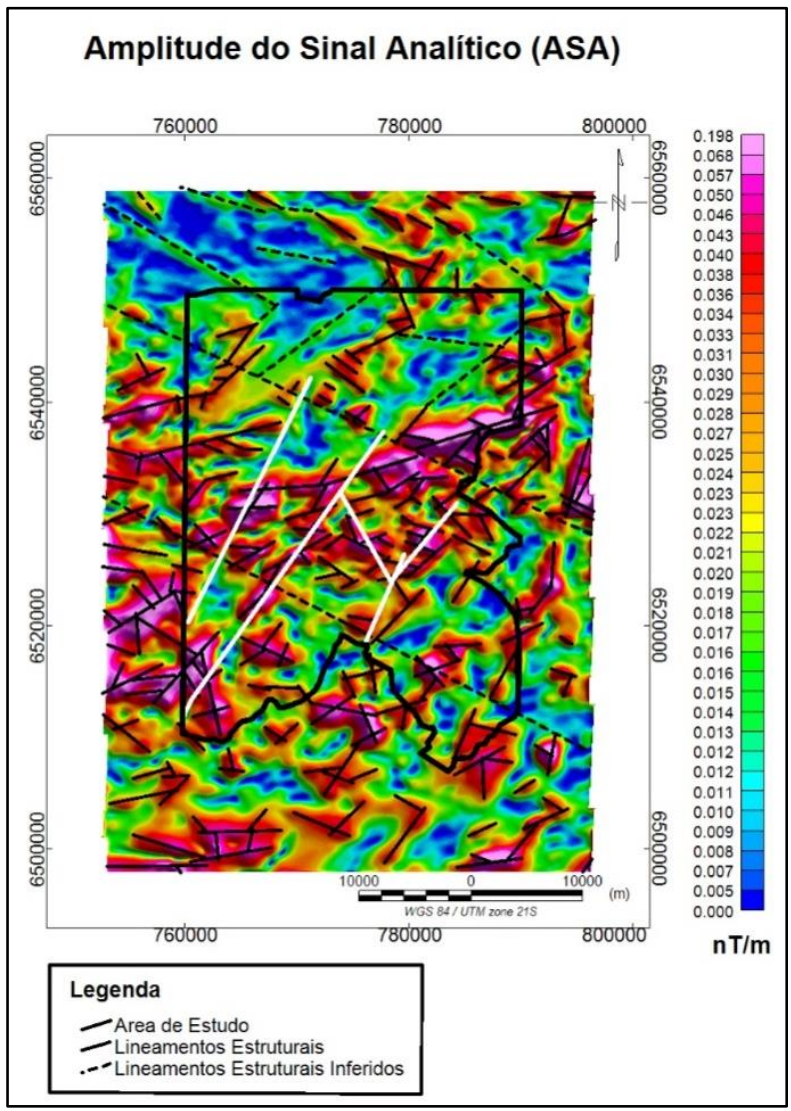

4.8. Integração dos Dados de Lineamentos e Análise do Arcabouço Estrutural

A análise estrutural de superfície e integração com os dados de subsuperfície foi realizada com a interpretação dos lineamentos das imagens SRTM na escala 1:500.000, das morfoestruturas e sobre os diversos processamentos dos dados aerogeofísicos, sendo somente apresentados neste trabalho os mapas ASA e GZ, pois estes são melhores para uso na correlação com os dados de SRTM. A seguir, as informações integradas são apresentadas em um mapa passível de interpretação e comparação entre os dois métodos (Figura 8).

Ambos os produtos apresentam predomínio de estruturas na

\subsection{Gradiente Vertical (GZ)}

O mapa do Gradiente Vertical (GZ) apresenta as estruturas magnéticas na escala 1:430.000. Neste foram identificados cerca de 215 lineamentos (Figura 7), com direção preferencial Nordeste e Noroeste sendo as principais orientações, nestas direções gerais, N60-70W e N50-80E.

As estruturas denominadas de "Inferidas" correspondem as feições magnéticas fora do intervalo de valores máximos, mas que apresentavam continuidade. Também foi Inferida uma grande estrutura cortando e gerando descontinuidade das principais estruturas magnéticas. Esta foi interpretada como uma estrutura transcorrente, e se apresenta mais nítida da Figura 7.

Figura 7- Mapa do arcabouço magnético-estrutural com a interpretação dos lineamentos identificados (linha contínua) e inferidos (linha tracejada).

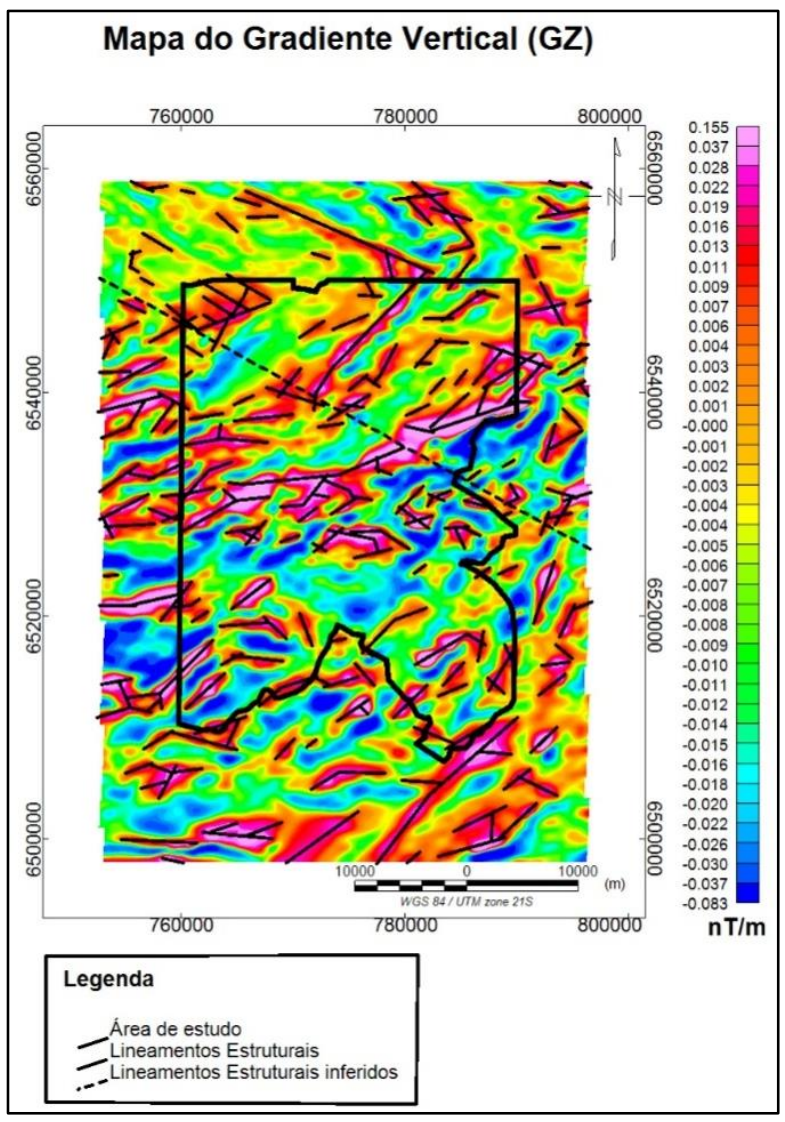

direção NE, o que revela que esta é a principal direção estrutural na área de estudo. Nos mapas magnéticos foi reconhecido um maior número de estruturas, principalmente na direção NW em comparação com os dados SRTM. Desta forma, para esta escala analisada os produtos aeromagnéticos gerados se mostram mais eficientes do que o SRTM.

A partir da integração dos dados das imagens SRTM e dos dados aeromagnéticos foi possível evidenciar a compartimentação estrutural da área de estudo, como resultado da interpretação dos grandes lineamentos. Essa compartimentação foi definida com base nos lineamentos interpretados na escala 1:1.000.000, com isso dividindo a área em blocos denominados de zonas: Z1, Z2, Z3, Z4 e Z5 (Figura 9 e Figura 10). 
Figura 8 - Mapa da análise estrutural de superfície e integração com os dados de subsuperfície

\section{ANÁLISE DOS LINEAMENTOS DE SUPERFÍCIE E INTEGRAÇÃO COM DADOS DE SUBSUPERFÍCIE}
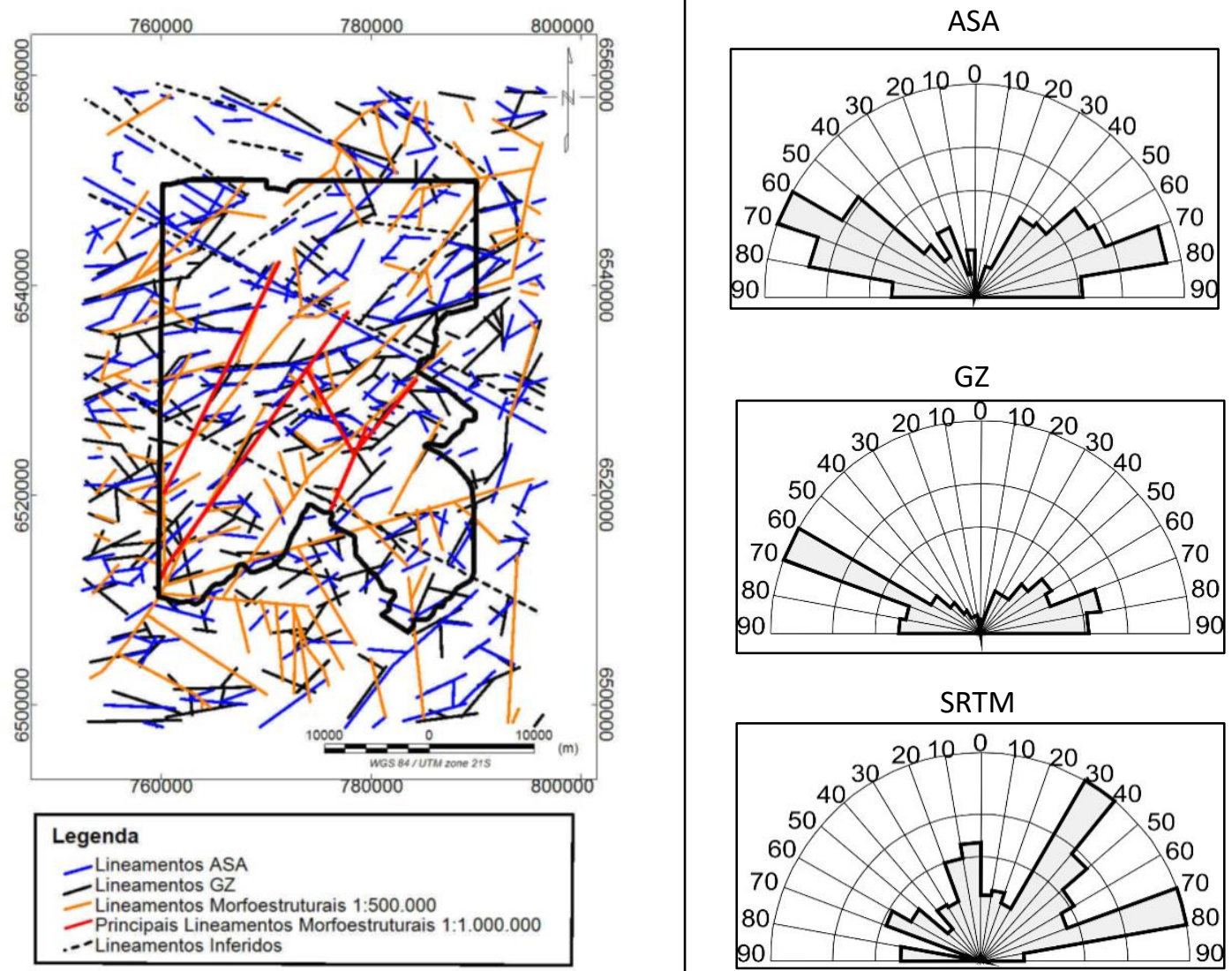

Figura 9- Mapa das Zonas Estruturais feitos com base na análise de lineamentos

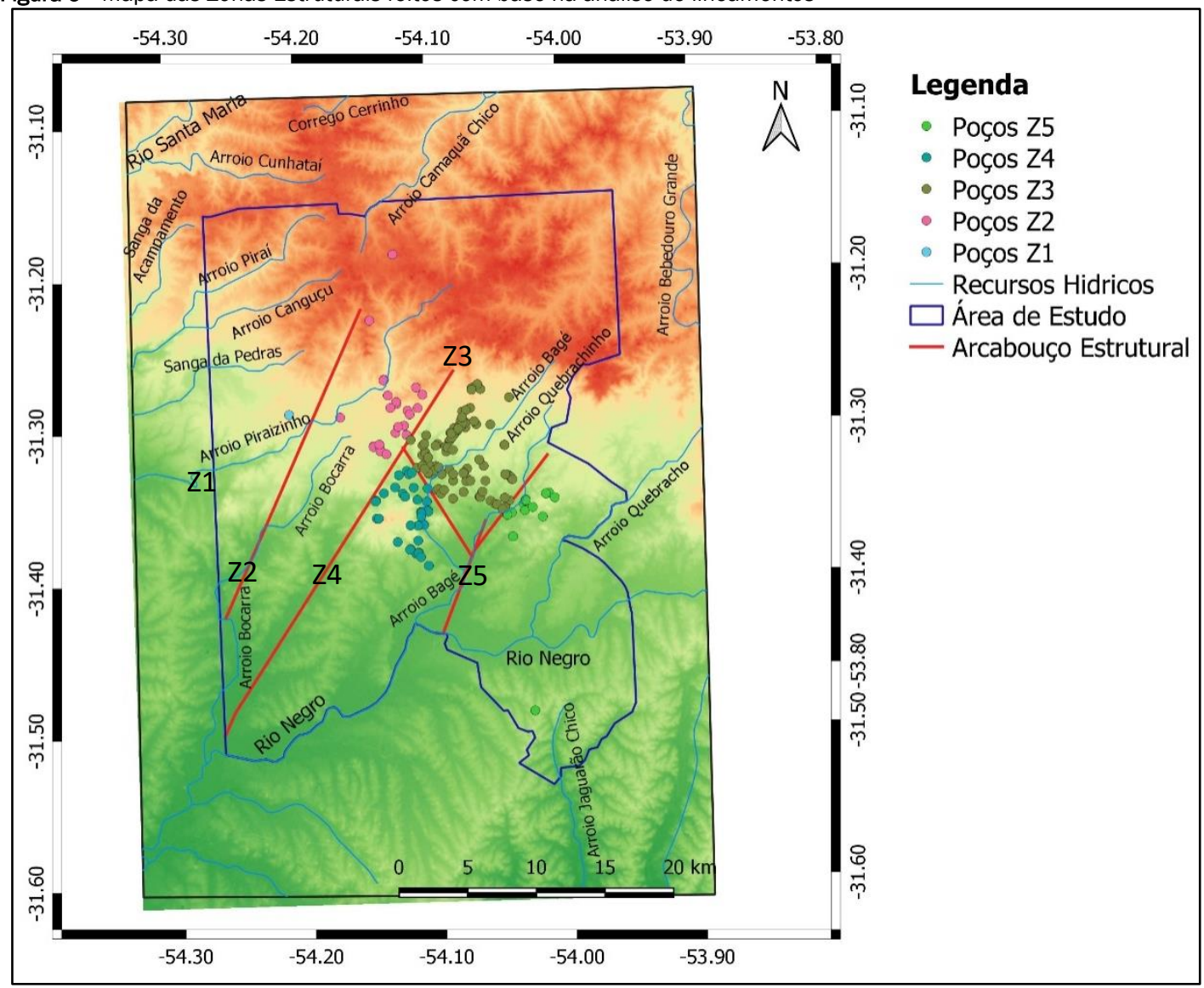


Figura 10 - Diagramas de Roseta por zonas

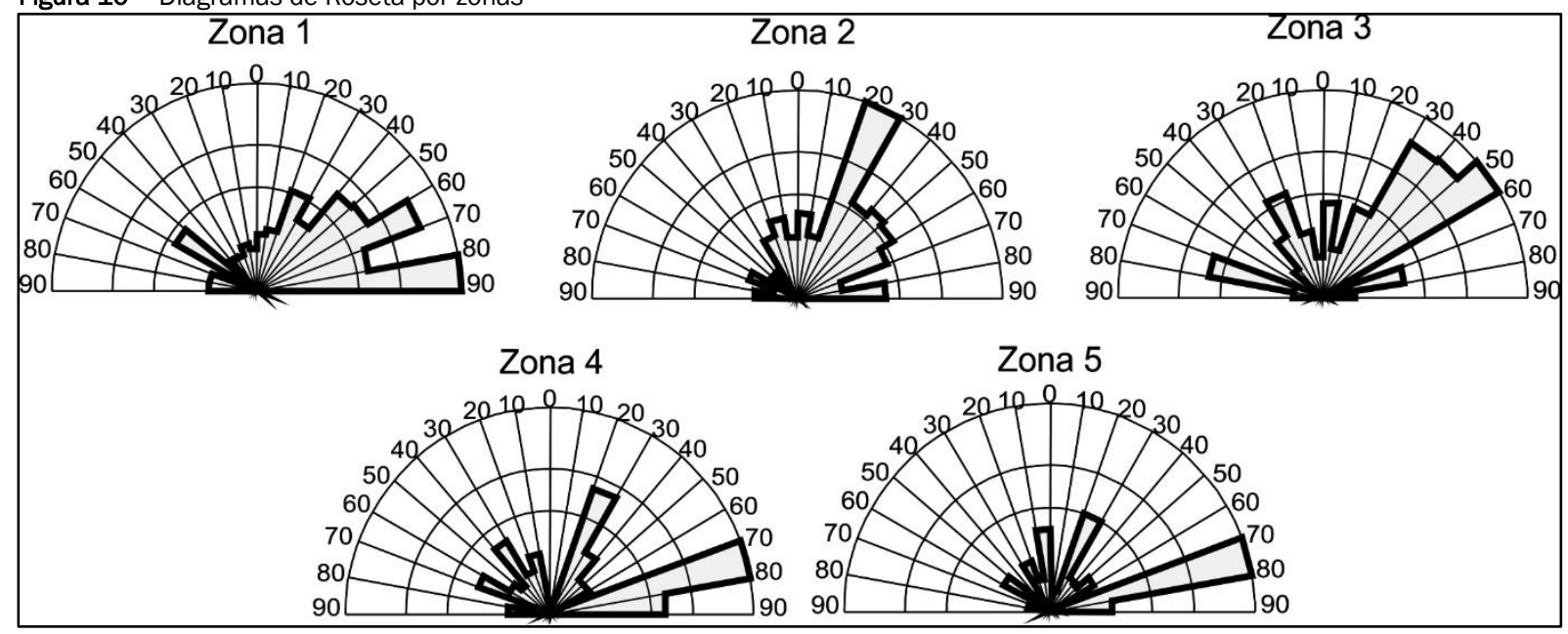

A análise das diferentes zonas permitiu a identificação das seguintes características:

1. Zona 1: caracteriza-se por lineamentos de médio a pequeno porte, em relação aos que compartimentaram a área de estudo, com predomínio na direção NE (Figura 10). Os principais trends para esta porção da área de estudo são N8090E (12 lineamentos), N60-70E (7 lineamentos) e N50-60E (4 lineamentos).

2. Zona 2: apresenta uma maior quantidade de estruturas de médio porte em relação as de pequeno porte. Esta área apresenta direção preferencial das estruturas para $\mathrm{NE}$, com os principais trends para N2O-30E (5 lineamentos), N40-50E (6 lineamentos) e N50-60E (4 lineamentos).

3. Zona 3: apresenta uma homogeneidade nas estruturas de médio e pequeno porte, com prodominio para a direção geral NE. As direções preferenciais são N50-60E (12 lineamentos), N40$50 \mathrm{E}$ (9 lineamentos) e N3O-40E (8 lineamentos).

4. Zona 4: composta por predomínio de lineamentos de pequeno porte, em relação aos de médio porte. Esta área tem direção geral principal para nordeste, com os principais trends para N70-80E (12 lineamentos), N20-30E (6 lineamentos) e N80-90E (5 lineamentos).

5. Zona 5: composto principalmente por lineamentos de médio porte e secundariamente de pequeno porte. Este compartimento apresenta predomínio da direção geral nordeste, mas com um pico na direção norte-noroeste, com os principais trends para N70$80 \mathrm{E}$ (12 lineamentos), N20-30E (4 lineamentos) e No0-10W (3 lineamentos).

\subsection{Análise Hidrogeológica e Relação com a Compartimen- tação Estrutural}

A análise hidrogeológica foi realizada com base na avaliação do banco de dados de poços, cujos resultados que representam o comportamento do sistema aquífero embasamento cristalino na região, são apresentados na Tabela 1 e na análise da frequência acumulada da capacidade específica por zonas para uma melhor distinção das zonas.

Tabela 1 - Caracterização geral dos 174 poços da área de estudo

\begin{tabular}{|c|c|c|c|c|c|}
\hline & Máximo & Mínimo & Média & Mediana & Desvio Padrão \\
\hline Profundidade final (m) & 200 & 15 & 75,12 & 71,50 & 34,81 \\
\hline $\begin{array}{l}\text { Nível Estático }(\mathrm{m}) \\
\text { Profundidade de }\end{array}$ & 80 & 0 & 8,51 & 6,55 & 9,08 \\
\hline Entradas de Água (m) & 45 & 15 & 29,63 & 25,50 & 10,95 \\
\hline $\begin{array}{l}\text { Número de Entradas d'água } \\
\text { Capacidade Específica }\end{array}$ & 5 & 1 & 2,17 & 2,00 & 1,17 \\
\hline $\begin{array}{c}\left(\mathrm{m}^{3} / \mathrm{h} / \mathrm{m}\right) \\
\text { Vazão }\end{array}$ & 35,00 & 0,01 & 1,24 & 0,16 & 4,67 \\
\hline$\left(m^{3} / h\right)$ & 125 & 0,13 & 5,36 & 2,90 & 13,51 \\
\hline
\end{tabular}

Com base nos dados apresentados na Tabela 1, observa-se que os poços perfurados na região, apresentam diferentes profundidades, localizadas entre 15 e $200 \mathrm{~m}$. Esses poços podem interceptar entre 1 e 5 fraturas (representadas pelas entradas de água), sendo que a profundidade de ocorrência dessas entradas está situada entre 15 e $45 \mathrm{~m}$, evidenciando que nessas profundidades há maior chance de ocorrência de estruturas abertas. Isso possui relação com a profundidade dos poços, pois tanto os valores de média $(75,12 \mathrm{~m})$, como mediana $(71,5 \mathrm{~m})$, estão próximos desses intervalos. Assim, poços mais profundos tem menos chance de interceptar estruturas, por isso são menos frequentes na região.

A análise dos dados de nível estático evidencia que a água que circula pelos aquíferos fraturados, na área de estudo, está localizado mais próximo da superfície, conforme pode ser observado nos valores de média $(8,51 \mathrm{~m})$ e mediana $(6,55 \mathrm{~m})$.

A avaliação dos dados gerais de capacidade específica, indica a ocorrência de valores muito diferentes, com variação entre 
0,01 a 35 m³/h/m. Essa variação acaba tendo reflexo nos valores de média e desvio padrão, por isso a mediana acaba refletindo melhor a produtividade do aquífero. Além disso, devese destacar que essa variação encontrada para os parâmetros estatísticos, está relacionada com as condições anisotrópicas do Sistema Aquífero Embasamento Cristalino, pois dependendo dos tipos de estruturas (orientação, comprimento, densidade, conexão, entre outras características), haverá diferentes capacidades de produção dos poços. No entanto, valores baixos de capacidade específica, para aquíferos fraturados associados a rochas graníticas, já foram identificados em diferentes estudos, como os realizados por Fernandes (2008), Machado e Freitas (2005), Gofferman et al. (2015).

A avaliação hidrogeológica dos compartimentos estruturais foi realizada com base na avaliação do parâmetro capacidade específica (Tabela 2). A Zona 1, por conter dados de apenas um poço, não foi incluída na análise estatística.

Tabela 2 - Caracterização da capacidade específica $\left(\mathrm{m}^{3} / \mathrm{h} / \mathrm{m}\right)$ por Zonas

\begin{tabular}{ccccc}
\hline & Z2 & Z3 & Z4 & Z5 \\
\hline Máximo & 6,933 & 3 & 2,133 & 1,5 \\
Mínimo & 0,087 & 0,016 & 0,009 & 0,035 \\
Média & 1,298 & 0,411 & 0,424 & 0,556 \\
Mediana & 0,121 & 0,175 & 0,157 & 0,255 \\
Desvio Padrão & 2,453 & 0,632 & 0,587 & 0,625 \\
Total de Poços & 22 & 102 & 35 & 14 \\
\hline
\end{tabular}

Conforme os dados expostos na tabela anterior, pode-se observar que as diferentes zonas apresentam comportamentos semelhantes com relação a capacidade específica. Se analisarmos os dados das médias, observa-se que a Zona 2 possui os maiores valores, seguido pela Zona 5 que apresenta um valor um pouco superior as Zonas 3 e 4 .

Se avaliarmos a distribuição da frequência do parâmetro capacidade específica e relacionar com as zonas identificadas (Figura 11), é possível observar melhor o comportamento de cada uma das zonas. Observa-se que todas as zonas apresen- tam a maior distribuição da frequência para valores inferiores a $1 \mathrm{~m}^{3 / \mathrm{h}} / \mathrm{m}$, mas possuem comportamentos diferentes para intervalos superiores de capacidade específica. A zona 2 é a única que apresenta a ocorrência de valores de capacidade específica superiores a $3 \mathrm{~m}^{3} / \mathrm{h} / \mathrm{m}$. Para o intervalo de valores de 2 a $3 \mathrm{~m}^{3} / \mathrm{h} / \mathrm{m}$, a zona 2 continua apresentando a maior frequência, seguido pelas zonas 4 e 3 . A zona 5, que apresentou valores de mediana um pouco mais elevados, só apresenta valores de capacidade específica para intervalos inferiores a $2 \mathrm{~m}^{3} / \mathrm{h} / \mathrm{m}$.

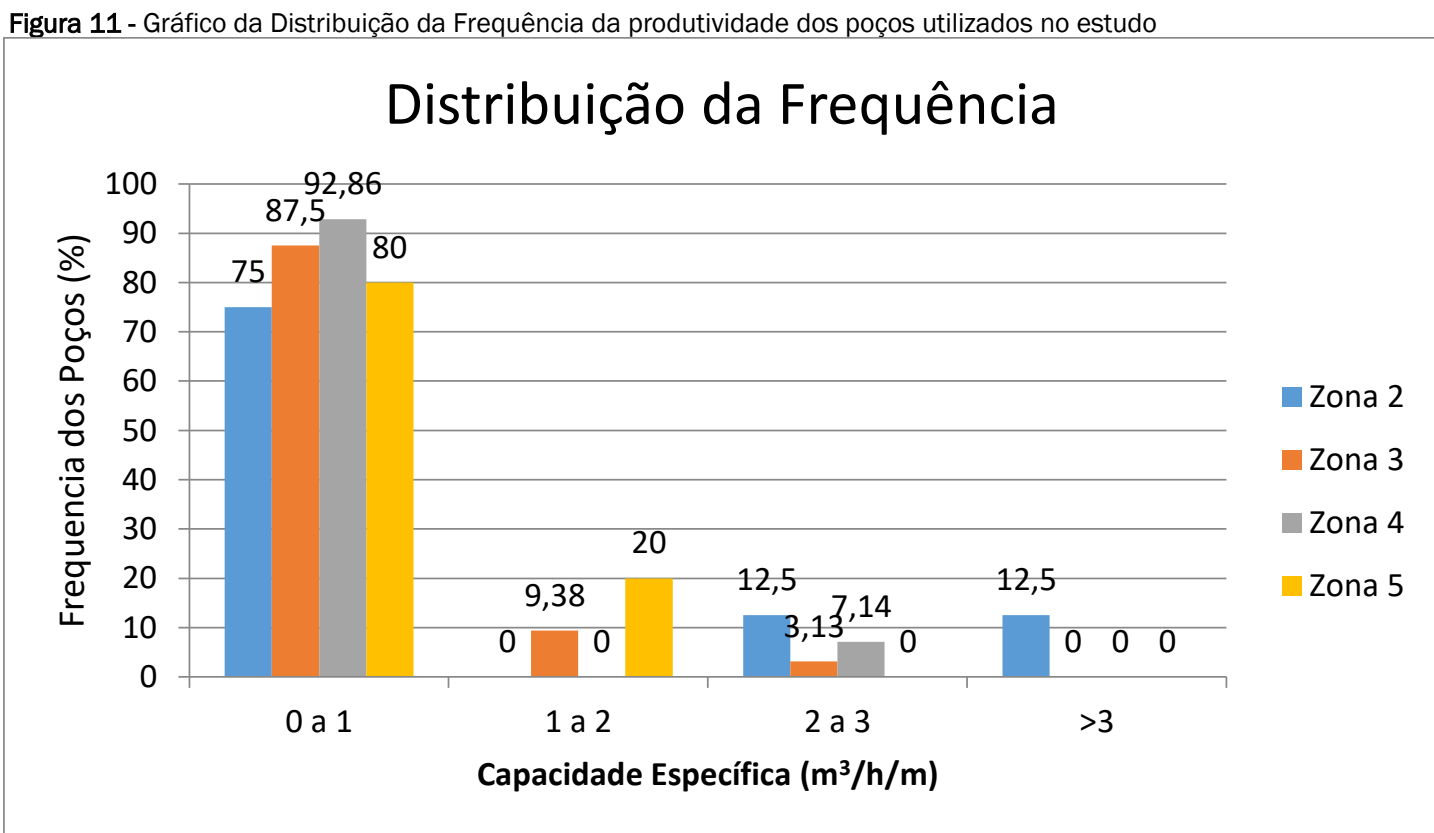

A figura 12 mostra a relação entre a capacidade específica e os lineamentos morfoestruturais e magnéticos, em cada uma das zonas.

Na zona 2 as morfoestruturas e lineamentos magnéticos, relacionados com os poços com maior capacidade específica $(1,4-2,8$ e 5,5 - 6,9 m³/h/m) apresentam as direções NE, para SRTM e o mapa ASA, bem como NW no mapa GZ.
A zona 3 compreende a maior quantidade dos poços com capacidade específica variando de baixa a alta, onde é possível observar um lineamento morfoestrutural relacionado com os poços mais produtivos, na direção NE. Enquanto os lineamentos magnéticos apresentam dois ou mais lineamentos relacionados a esses poços, com 2 lineamentos para NW e um NE no mapa de ASA e três NW no mapa GZ. 
A zona 4 apresenta um poço com capacidade específica relacionado com valor médio $\left(1,4-2,8 \mathrm{~m}^{3} / \mathrm{h} / \mathrm{m}\right)$, sendo que este ocorre relacionado apenas com os lineamentos magnéticos. Nos mapas magnéticos foram identificados dois lineamentos em ASA, um NW e um NE, e um lineamento em GZ, na direção
NE.

Na zona 5 ocorrem poços com baixa produtividade $(0,0$ - 1,4 $\left.\mathrm{m}^{3} / \mathrm{h} / \mathrm{m}\right)$ e um com valor médio $\left(1,4-2,8 \mathrm{~m}^{3} / \mathrm{h} / \mathrm{m}\right)$, que estão associados a lineamentos magnéticos de direção NW.

Figura 12 - Mapa de Lineamentos relacionados com os maiores valores de Capacidade Específica

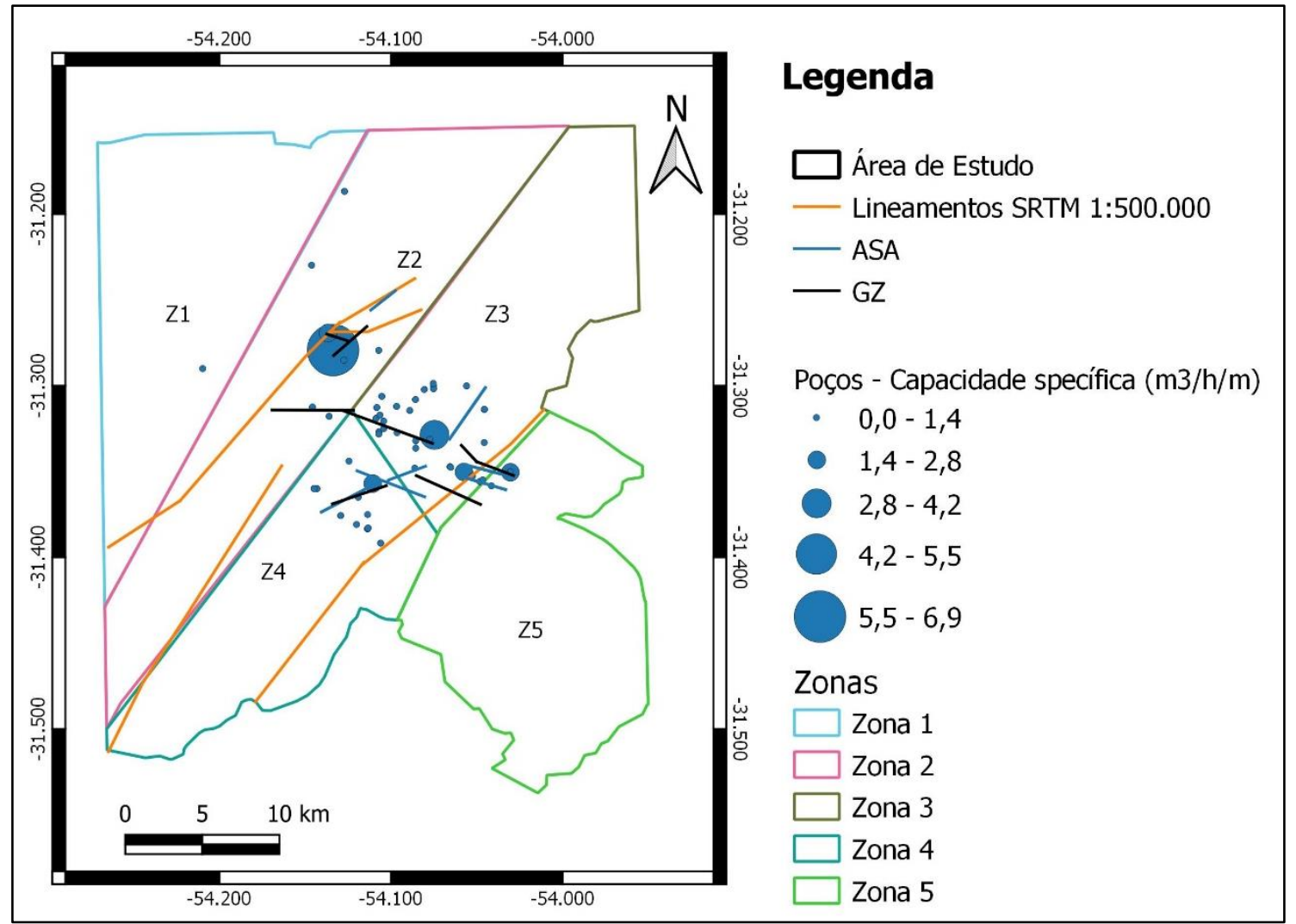

\subsection{Caracterização Estrutural e Hidrogeológica das Zonas}

Com base nos dados apresentados nos itens anteriores, foi possivel avaliar e caracterizar cada uma das zonas definidas, com relação aos aspectos estruturais e hidrogeológicos:

1. Zona 1: apresenta comportamento estrutural nordeste e predomínio para as direções N80-90E, seguido de N60-70E. Com relação a hidrogeologia não há como fazer maiores avaliações, pois nessa área só há ocorrência de um poço que apresentou uma capacidade específica baixa de $0,005 \mathrm{~m}^{3} / \mathrm{h} / \mathrm{m}$;

2. Zona 2: apresenta comportamento estrutural predominante para nordeste, com trend principal N2O30E. Esta se caracteriza por uma capacidade específica máxima de $6,933 \mathrm{~m} 3 / \mathrm{h} / \mathrm{m}$ e pela ocorrência de valores mais elevados, acima de $2 \mathrm{~m}^{3} / \mathrm{h} / \mathrm{m}$;

3. Zona 3: composta por direção geral preferencial para nordeste, com predomínio para N50-60E, seguidas pelas orientações N40-50E e N30-40E. Essa zona é caracterizada por apresentar valores de média e mediana de capacidade específica iguais a 0,411 e $0,175 \mathrm{~m}^{3} / \mathrm{h} / \mathrm{m}$, respectivamente. Embora a maior parte dos valores de capacidade específica seja inferior a $1 \mathrm{~m}^{3} / \mathrm{h} / \mathrm{m}$, há ocorrência de poços que apresentam valores entre 1 e $3 \mathrm{~m}^{3} / \mathrm{h} / \mathrm{m}$;

4. Zona 4: caracteriza-se por estruturas gerais na direção nordeste, principalmente para N70-80E, seguidas de orientações para N20-30E. As capacidades específicas encontradas indicam valores de média igual a $0,424 \mathrm{~m}^{3} / \mathrm{h} / \mathrm{m}$ e de mediana igual a $0,157 \mathrm{~m}^{3} / \mathrm{h} / \mathrm{m}$. Essa zona possui a maior distribuição de valores de capacidade específica inferiores a $1 \mathrm{~m}^{3} / \mathrm{h} / \mathrm{m}$, mas apresenta poços com valores entre 2 e $3 \mathrm{~m}^{3} / \mathrm{h} / \mathrm{m}$;

5. Zona 5: apresenta comportamento estrutural para nordeste, com orientações para N70-80E, seguido de outras orientações para N20-30E e NOO-10W. Essa zona apresenta os maiores valores de média $\left(0,556 \mathrm{~m}^{3} / \mathrm{h} / \mathrm{m}\right)$ e mediana $\left(0,255 \mathrm{~m}^{3} / \mathrm{h} / \mathrm{m}\right)$ da capacidade específica. No entanto, há maior ocorrência para valores inferiores a $1 \mathrm{~m}^{3} / \mathrm{h} / \mathrm{m}$ e ausência para intervalos maiores.

\section{CONCLUSÃO}

Os métodos aqui empregados, como a integração dos dados aeromagnéticos, levantamento de lineamentos em imagem 
SRTM e análise hidrogeológica, permitiu avaliar o comportamento local do Sistema Aquífero Embasamento Cristalino.

A área de estudo foi dividida em cinco compartimentos estru turais e hidrogeológicos, a partir da integração dos dados superficiais (SRTM) e subsuperficiais, com as técnicas geofísicas aplicadas ao campo magnético anômalo (ASA e GZ), através do reconhecimento dos grandes lineamentos. Estes dois métodos apresentaram boa correlação dos lineamentos magnéticos estruturais e morfoestruturas mapeados nas escalas utilizadas neste trabalho. Desta forma, estes dados forneceram indicações de trends preferenciais que condicionam a ocorrência de aquíferos fraturados, sendo os mesmos localizados na direção geral nordeste, preferencialmente N30-40E e N70$80 \mathrm{E}$, e noroeste N60-70W, que não foi observado nos dados SRTM.

Com base na análise hidrogeológica foi possivel ordenar as zonas mais favoráveis à perfuração de poços tubulares profundos. A partir da análise dos valores de capacidade específica, observa-se que as zonas que apresentam maior produtividade dos poços, são em ordem decrescente de importância as zonas 2, 3, 4, 5 e 1. Em relação a estruturas que estão associadas a poços mais produtivos, observa-se que na zona 2 a principal orientação é N20-30E, na zona 3 é N60-70W e N50-60E, enquanto que na zona 4, as orientações são N7080E e N20-30E e na zona 5 a principal orientação é N70-80E.

Ainda assim, compreende-se a necessidade de um reconhecimento geológico (mapeamento) de detalhe associado a métodos indiretos de investigação como eletrorresistividade ou eletromagnético para avaliar melhor as estruturas, a possibilidade de ocorrência de água subterrânea e definir no campo, os locais mais favoráveis para a perfuração de poços mais produtivos.

\section{REFERÊNCIAS}

AB'SABER, A. N. Mega geomorfologia do território brasileiro. In: CUNHA, S. B.; GUERRA, A. J. T. Geomorfologia do Brasil. Rio de Janeiro: Bertrand Brasil, 1998. p. 71-106.

BERLATO, M. A. As condições de precipitação pluvial no estado do Rio Grande do Sul e os impactos das estiagens na produção agrícola. In: BERGAMASCHI, H.; BERLATO, M. A.; FONTANA, D. C.; CUNHA, G. R.; SANTOS, M. L. V. DOS; FARIAS, J. R. B.; BARNI, N. A. Agrometeorologia aplicada à irrigação. Porto Alegre: UFRGS, 1992, p.11-23.

BONGIOLO, A. B. S.; FERREIRA, F. J. F.; BITTENCOURT, A. V. L.; SALAMUNI, E. Connectivity and magnetic-structural compartmentalization of the Serra Geral and Guarani aquifer systems in central state of Paraná (Paraná Basin, Brazil). Revista Brasileira de Geofísica, v. 32, n. 1, 2014.

CAMOZZATO, E.; KLEIN, C.; IGLESIAS, C. M. da F. Bagé, Folha S H.21-ZD-III BAGÉ. Estado do RS. Porto Alegre: CPRM. Carta Geológica, Escala 1:100.000. Programa Geologia do Brasil PGB. 2014.

CPRM - SIAGAS. http://siagasweb.cprm.gov.br/layout/apresentacao.php. Acesso em: 24 ago. 2016.
CPRM - Projeto Aerogeofísico Escudo do Rio Grande do Sul, 2010. Disponível em: http://rigeo.cprm.gov.br/xmlui/handle/doc/10948?show=full. Acesso em: 24 ago. 2016.

CASTRO, L. G. Arcabouço geofísico estrutural da porção meridional do Cinturão Ribeira e Regiões Adjacentes. 2014. Tese (Doutorado) - Programa de Pós-Graduação em Geologia, Universidade Federal do Paraná - Curitiba, 204p, 2014.

DAEB - Departamento de Água, Arroio e Esgoto de Bagé. Disponivel em: http://www.daeb.com.br/7/Agua.html. Acesso em: 22 ago. 2018.

DRH/FEPAM - Sistema de Outorga de Água Subterrânea do Rio Grande do Sul (SIOUT). Disponível em: http://www.siout.rs.gov.br/\#/. Acesso em: 14 ago. 2018.

FERNANDEA, A. J. Aquíferos Fraturados: uma revisão dos condicionantes geológicos e dos métodos de investigação. Revista do Instituto Geológico, São Paulo, v. 29, n 1/2, 49-72, 2008.

FERREIRA, F. J. F., SOUZA, J., BONGIOLO, A. B. S., CASTRO, L. G., ROMEIRO, M. A. T. Realce do Gradiente horizontal total de anomalias magnéticas usando a inclinação do sinal analítico. Parte I - Aplicação a dados sintéticos. In: SIMPÓSIO BRASILEIRO DA SBGF, 4., 2010. [Anais...]. Brasília, 2010.

FREITAS, M. A. Recursos hídricos subterrâneos. Geodiversidade do estado do Rio Grande do Sul. CPRM, Porto Alegre, 7187,2010

GEOSOFT. Tutorial. Disponivel em: file:///C:/Program\%20Files\%20(x86)/Geosoft/Oasis\%20montaj/hlp/onlinepdfs.htm. Acesso em: 22 ago. 2018.

GOFFERMANN, M.; VIERO, A.P.; SILVA. E. B. DA. Caracterização Hidrogeológica e hidroquímica das águas subterrâneas da região de São Gabriel, RS. Pesquisas em Geociências, v. 42, n. 3 - 239-261, 2015.

HEWAIDY, A. G. A., EL-MOTAAL, E. A., SULTAN, S. A., RAMDAN, T. M., EL KHAFIF, A. A., \& SOLIMAN, S. A. Groundwater exploration using resistivity and magnetic data at the northwestern part of the Gulf of Suez, Egypt. Egyptian Journal of Petroleum, v. 24, n. 3, 255-263, 2015.

IBGE. Mapa geomorfológico do Brasil. Escala1:5.000.000. Rio de Janeiro: IBGE, 1995.

LEIVAS, J. F., BERLATO, M. A., DENISE C. F. Risco de deficiência hídrica decendial na metade sul do Estado do Rio Grande do Sul. Revista Brasileira de Engenharia Agrícola e Ambiental. Campina Grande/PB. v. 10, n. 2, p. 397-407, 2006.

MACHADO, J. L. F., FREITAS, M. A. Mapa Hidrogeológico do Rio Grande do Sul. CPRM - Projeto Mapa Hidrogeológico do Rio Grande do Sul. Escala 1: 750.000, 2005.

PEREIRA, B. M., FERREIRA, F. J. F. Recognition of Golf Mineralization Favorability Zones Through Airbone Gamma-Ray Spectrometry and Magnetometry in Brusque and Botuverá Region, 
Southern Brazil. Brazilian Journal of Geophysics, v. 36, n. 3, set. 2018. Disponível em: https://sbgf.org.br/revista/index.php/rbgf/article/view/1953. Acesso em: 22 jan. 2019.

RANGANAI, R. T., MOIDAKI, M. D., KING, J. G., BAGAI, Z. B. Geophysical and Hydrogeological Groundwater Prospectivity Mapping in the Kraaipan Granite-Greenstone Terrain, Southeast Botswana. Journal of Water Resource and Protection, v. 9, 1270-1298, 2017.

SANTOS, J. C.; OKA-FIORI, C.; CANALI, N. E.; FIORI, A. P.; SILVEIRA, C. T.; SILVA, J. M. F.; ROSS, J. L. S. Mapeamento geomorfológico do estado do Paraná. Revista Brasileira de Geomorfologia, Brasília, v. 7, n. 2, p. 3-12, 2006.

TAMBARA, G. B. Geologia dos Granitóides Sanga Rasa, Terreno Taquarembó, Bagé, RS. Trabalho de Conclusão de Curso, UFRGS, Instituto de Geociências. Porto Alegre, 75p., 2013.
TOPODATA. Banco de dados geomorfométricos do Brasil. Disponivel em: http://www.dsr.inpe.br/topodata/index.php. Acesso em: 12 fev. 2018.

TRAININI et.al. Mapa hidrogeológico do Estado do Rio Grande do Sul, Escala 1: 750.000. Companhia de Pesquisa de Recursos Minerais, Poro Alegre, RS. 2005.

USGS. Disponivel em :https://www.usgs.gov/centers/eros/science/usgs-eros-archive-digital-elevation-shuttleradar-topography-mission-srtm-non?at-science center objects $=0$ \#qt-science center objects. Acesso em: 12 nov. 2017.

VARONE, F.; FERREIRA, S., ALVES, R. Análise de anos com estiagem na região de Bagé/RS. In: SIMPÓSIO INTERNACIONAL DE CLIMATOLOGIA, 4., 2011. [Anais...]. João Pessoa. 2011. 